\title{
Remotely identifying potential vector habitat in areas of refugee and displaced person populations due to the Syrian civil war
}

\author{
Samuel N. Chambers, ${ }^{1}$ Joseph A. Tabor ${ }^{2}$ \\ ${ }^{1}$ School of Geography \& Development; ${ }^{2}$ School of Natural Resources and the Environment, University of \\ Arizona, Tucson, AZ, USA
}

\begin{abstract}
Historically leishmaniasis is most prevalent in established urban centres but this research shows that refugees and, most significantly, internally displaced persons are now commonly in areas characterized by the presence of fly habitats potentially leading to higher prominence of Leishmania infection. Areas engulfed by the Syrian civil war has thus caused the dispersal of humans into previously unpopulated areas amid habitats of the sand fly Phlebotomus papatasi that hosts the parasite Leishmania. The addition of new places of exposure to this disease add to difficulties with respect to diagnosis as well as provision of care and treatment. We used geospatial methodology adapting it to remotely identifying and analyzing sand fly habitats with the aim of measuring how common it is. Our methodology helps avoid the issue of resolution in satellite imagery by measuring likelihood rather than strictly known locations. We followed up this information with spatial analysis identifying which civilian populations are most prone to sand fly exposure, and therefore leishmaniasis, due to their geographical situation. Our results suggest that those most
\end{abstract}

Correspondence: Samuel N. Chambers, School of Geography \& Development, University of Arizona, 1064 East Lowell Street, Tucson, AZ, USA.

Tel.: +1.520.465.1721

E-mail: schambers@email.arizona.edu

Key words: Remote sensing; Spatial analysis; Epidemiology; Refugee crisis; Leishmaniasis; Middle East.

Contributions:SNC primarily contributed to background, methods, and analysis. JAT contributed to interpretation.

Conflict of interest: the authors declare no potential conflict of interest.

Funding: none.

Received for publication: 12 January 2018.

Revision received: 11 September 2018.

Accepted for publication: 30 Septamber 2018.

(C) Copyright S.N. Chambers and J.A. Tabor, 2018

Licensee PAGEPress, Italy

Geospatial Health 2018; 13:670

doi:10.4081/gh.2018.670

This article is distributed under the terms of the Creative Commons Attribution Noncommercial License (CC BY-NC 4.0) which permits any noncommercial use, distribution, and reproduction in any medium, provided the original author(s) and source are credited. likely to be exposed to Leishmania are internally displaced persons, those camps less likely to receive medical relief and typically having temporary residents migrating elsewhere.

\section{Introduction}

Leishmaniasis, a parasitic protozoan disease spread by Phlebotomus papatasi sand flies is a major cause of infections and skin ulcers in times of war, both with regard to military staff (Cross et al., 1996) and to civilians (Hayani et al., 2015; Inci et al., 2015; Al-Salem et al., 2016; Özkeklikçi et al., 2017) The World Health Organization (WHO) reports that the disease is responsible for 20 to 30 thousand deaths in the world each year, with an estimated 900 thousand to 1.3 million cases annually (WHO, 2016). Historically, leishmaniasis has been documented as most prevalent among the impoverished in urban areas, often also common among military personal, in what is now northern Syria and southeastern Turkey (Schilling, 1921). The risk for Leishmania infection is a growing concern with the continuation of the Syrian Civil War and the associated refugee crisis (Hayani et al., 2015; Inci et al., 2015; Al-Salem et al., 2016; Özkeklikçi et al., 2017). An estimated 4.8 million Syrians have been displaced externally (Response, 2016). Refugee sites are located within areas with a relatively high probability of a high density of sand fly habitats, particularly in Lebanon, Kurdish Iraq and south-eastern Turkey, which have a long history of recorded cases of leishmaniasis (Pigott et al., 2014), while reports from Kurdish fighters suggest this as a relatively new phenomena in the rural areas (Rudaw, 2015). Although this new development has been locally attributed to the disposal of corpses (Rudaw, 2015; Mondragon-Shem and Acosta-Serrano, 2016), the high prevalence of leishmaniasis is likely the result of the absence of disease control programmes and disruption of health services due to the war (Mondragon-Shem and Acosta-Serrano, 2016).

Cross et al. (1996) developed a method based on remote sensing to predict the distribution of $P$. papatasi sand flies in the Middle East based on the Normalized Difference Vegetation Index (NDVI). These authors showed that the highest risk of exposure and spread of the disease was highest from May to October coinciding with NDVI values of 0 to 0.06 (Cross et al., 1996). The use of NDVI and land cover classification are well suited as low-cost rapid risk assessment of vector-borne illnesses (Brownstein, 2004). Our study expanded on this methodology in combination with a geospatial analysis of the likelihood of sand fly habitats near sites of refugees and displaced persons in Syria and bordering countries.People trapped within areas inaccessible to health care would theoretically be of particular concern if they were also located in an area with a high likelihood of exposure to the parasite. Such populations would be difficult to detect by health care 
providers increasing the risk for local outbreaks (Berkley, 2017). To identify such risks geographically in war-torn areas, methods would need to be rapid and, unlike traditional methods, rely almost entirely on remote assessment rather than sampling on-site vector populations (Diuk-Wasser et al., 2006). As shown by Brownstein et al. (2002), rapid assessment of vector-borne illness requires remote sensing and predicative models.

Leishmaniasis was typically confined to urban areas such as Aleppo, Syria (Yaman and Özbel, 2004) but cases have spread with occurrences among refugees (Al-Salem et al., 2016). One of the biggest limitations to an analysis of the current leishmaniasis status in refugee and displaced populations is the difficulty gathering accurate information due to the Syrian Civil War (Du et al., 2016). This analysis seeks to circumvent that problem by relying on place and likelihood of habitat rather than documented records, which are difficult to collect and maintain during war and mass migration. The question becomes a question of exposure to infected sand flies. This study seeks to answer that with applied remote sensing and a statistical analysis of known populations, and their locations, impacted by the Syrian civil war.

\section{Materials and Methods}

Within our study area, with a centroid location of $35.65 \mathrm{~N}$ and 39.71 E, we developed a remote sensing model based on Moderate Resolution Imaging Spectroradiometer (MODIS) data acquired by the satellites Terra and Aqua belonging to the Earth Observing System developed by the US National Aeronautics and Space Administration (NASA). The eMODIS data collection (Hansen et al., 2004) provided the normalized difference vegetation index (NDVI) based on visible and near-infrared bands of the electromagnetic spectrum which is capable of measuring the presence of live green vegetation in a $250 \times 250 \mathrm{~m}$ resolution (Rouse et al., 1973). MODIS NDVI has a range of values from -1 to +1 by the formula (NDVI-4000)/6000. All values from 0 to 0.06 coincided with sand fly habitat locations as shown in previous analyses (Cross et al., 1996). We converted these continuous spatial data to point locations with a 250 meter Kernel density, i.e. the density of points surrounding each point (Bithell, 1990; Silverman, 2018), to identify the areas of highest probable density of habitats (PDH). The Kernel density gives a smoothed map where we can infer habitat density based on the spacing of detected locations. The neighbourhood radius is standard to kernel density by geospatial analysis and determined by the formula (Eq. 1):

$$
R=0.9 * \min \left(S D, \sqrt{\frac{1}{\ln (2)}} * D m\right) * n^{-0.2}
$$

where $S D$ is the standard distance, $D m$ the median distance, and $n$ the number of points. Standard distance was calculated as (Eq. 2):

$$
S D=\sqrt{\left(\frac{\sum_{i=1}^{n}\left(x_{i}-\bar{X}\right)^{\wedge} 2}{n}\right)+\left(\frac{\sum_{i=1}^{n}\left(y_{i}-\bar{X}\right)^{\wedge} 2}{n}\right)}
$$

where $x i$ and $y i$ are the coordinates for the point, with and repre- senting the mean centre, and $n$ the number of points (Mitchel, 2005). We did this for the month of June 2015 since this month represents the peak season for sand fly dispersal in the region (Cross et al., 1996; Orshan et al., 2010). Areas of zero kernel density values, were considered as having a near zero or lower probability of containing sand fly habitats at the time. PDH values were extracted by point locations for known refugee locations (mostly official United Nations camps), known as Internally Displaced Persons (IDP) camps, and the major cities of Syria for those persons still confined there.

\section{Results}

Every refugee camp location was found to be situated within a sand fly habitat. A visual inspection of the model (Figure 1) suggests that the camps near Antakya, Turkey were especially at risk with high PDH and relatively near past cases of leishmaniasis according to data collected by Pigott et al. (2014).

In 2014, there were an estimated 6.8 million IDPs within Syria (Sharara and Kanj, 2014). The majority of these were shown to be in locations near the Turkey and Lebanon borders or outside cities. However, the two IDP camps on the south-eastern border with Jordan showed a PDH of zero. The details of leishmaniasis cases is lacking for IDPs except for some unverified information from Kurdish soldiers (Rudaw, 2015). What is evident from the PDH is that the IDPs are at high risk, but unlike the refugee camps, the reality on the ground is less clear (Figure 2).

An analysis of the major Syrian cities shows that all but one were situated within low to high PDH areas. Like the IDP camps, the details on the ground are less certain (Figure 3).

A single-factor ANOVA (Sokal and Rohlf, 1969) shows IDP camps as the overall highest average PDH values with the major cities having the lowest. However, with their wide distribution across the borders, the refugee sites did have the highest variance. The P-value is less than the $\alpha$ of 0.05 , so the Refugee Sites, IDP camps, and the cities are significantly different with regard to their PDH values. A post-hoc Least Significant Difference (LSD) anal-

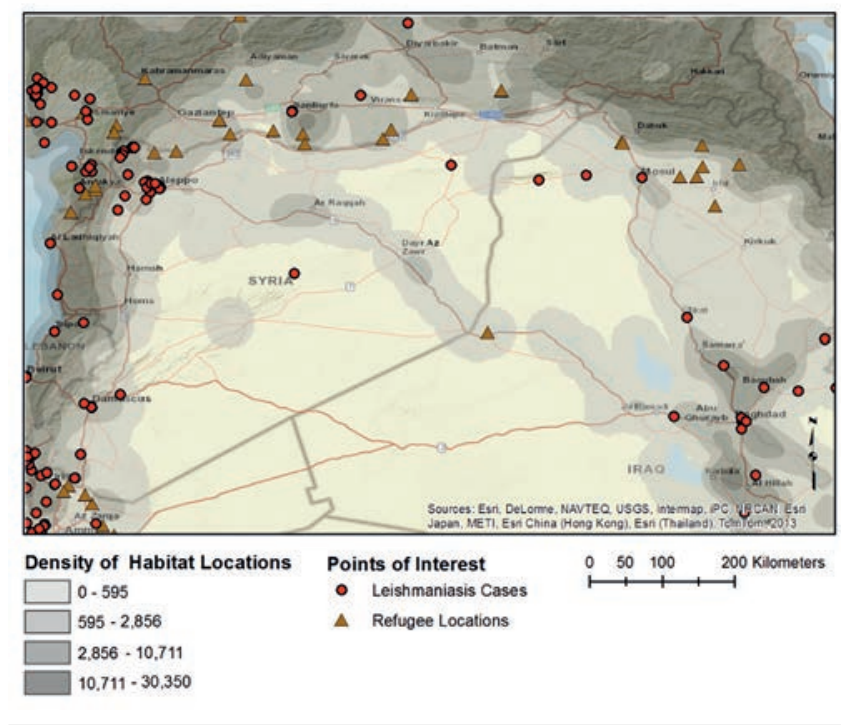

Figure 1. Probable density of habitats (in points per $\mathrm{km}^{2}$ ) in relation to refugee locations and historically known points of occurrence of leishmaniasis (data derived from Pigott et al., 2014). 
ysis of the ANOVA values showed each site group being significantly different from all other group. This shows that, those persons overwhelmingly most likely to be exposed to Leishmania are those displaced in camps within Syria.

Boxplots show a large fourth quarter for refugee sites with an even greater outlier (Altinozu 1, Hatay province, Turkey) and a larger range than the IDP camps. Cities also show outliers (Tartus and Latakia, Syria) reaching as high as the third quartile of IDP camps, but with a much smaller median that is below the first quartile of the IDP camps. The maximum PDH values for IDP camps were in the Khirbat al Jawz IDP Camps 1 \& 2 (Idlib Governorate, Syria) (Table 1).

Outliers include Tartus (127), Latakia (123), and Altinozu 1 (30) (Figure 4).

Histograms suggest these outliers and differing ranges as resulting from the bimodal distribution of each location variable. Each variable has sites within high and low PDH values but IDP camps have a larger number of records with moderate PDH values, while Refugee sites have the overall highest PDH values but also the highest amount of low PDH values, which demonstrates the importance of individual site condition in planning and observation (Figure 5).

\section{Discussion}

With the conflict and movement of people, leishmaniasis has begun to be documented within refugee camps (Al-Salem et al., 2016). Our results support this including the sudden jump in new cases in Lebanon from 6 in the 2000-2012 period to 1,033 in 2013, $96 \%$ of which were among Syrian refugees (Alawieh et al., 2014). There is also the issue of new Leishmania species introduced into areas with large population migration (Koltas et al., 2014). All of this suggests that a combination of the following factors: i) lack of health care; ii) likelihood e of sand fly habitats and; iii) mass

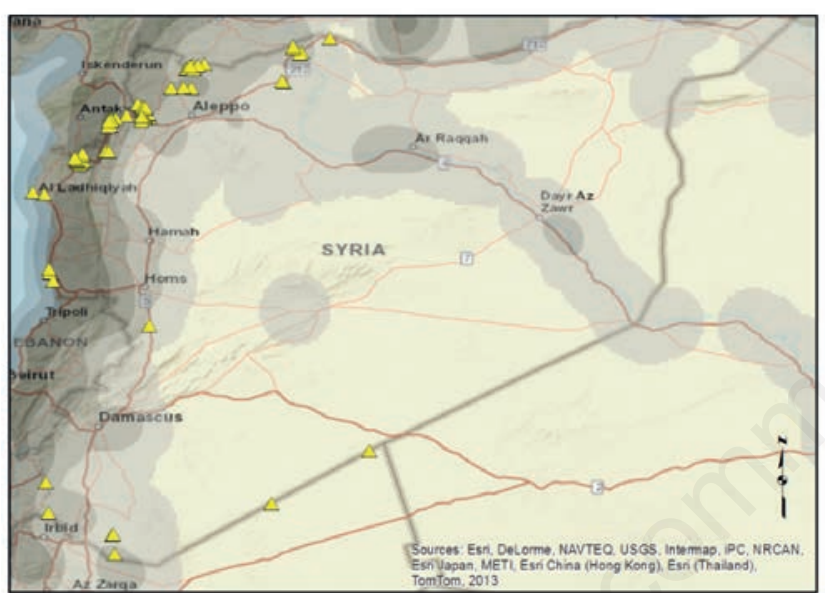

Density of Habitat Locations Points of Interest $\begin{array}{llllll}0 & 37.5 & 75 & 150 \text { Kilometers }\end{array}$

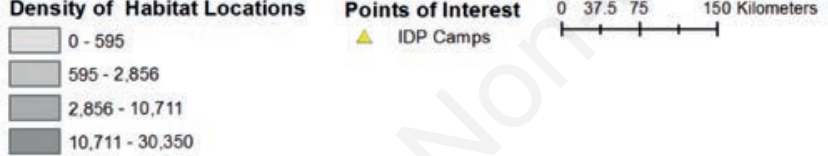

Figure 2. Probable density of habitats (in points per $\mathrm{km}^{2}$ ) in relation to internally displaced persons (IDP) camps (data derived from Pigott et al., 2014).

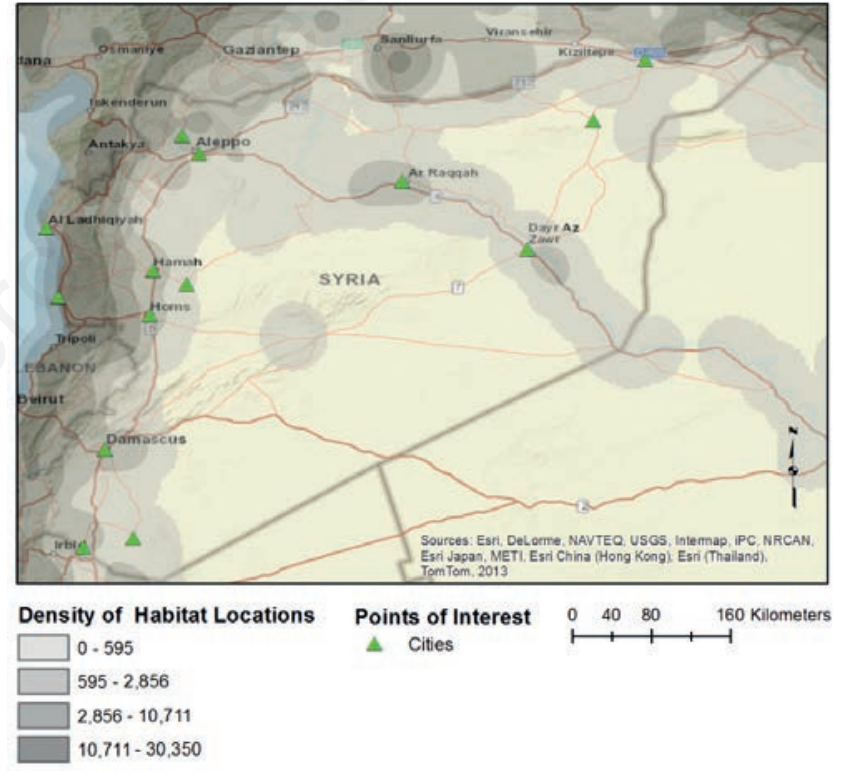

Figure 3. Probable density of habitats (in points per $\mathrm{km}^{2}$ ) in relation to Syrian cities (data derived from Pigott et al., 2014).

Table 1. Summary of probable density of habitats values for refugee sites, internally displaced persons camps (IDP), and Syrian cities.

\begin{tabular}{|c|c|c|c|c|}
\hline $\begin{array}{l}\text { ANOVA } \\
\text { Source of variation }\end{array}$ & $\mathrm{SS}^{\mathrm{a}}$ & $d_{f} f^{b}$ & $\mathrm{MS}^{\mathrm{c}}$ & $F^{d}$ \\
\hline Between groups & 203416385 & 2 & 101708193 & 4 \\
\hline Within groups & 3463191830 & 128 & 27056186 & - \\
\hline \multirow[t]{2}{*}{ Total } & 3666608215 & 130 & & - \\
\hline & Refugees \& IDP & Refugees \& cities & IDP \& cities & . \\
\hline Least Significant Difference & 1,863 & 2,976 & 2,796 & - \\
\hline Difference & 35 & 27 & 62 & - \\
\hline
\end{tabular}


migration of persons contribute to the increase of Leishmania cases in refugees. The latter factor has two outcomes: settlement of refugees in camps and spread through migration, which ultimately means that the routes and sites matter when planning for the health care and understanding future threats.

The rapid risk assessment methodology we developed provides a spatial epidemiological use for planning relief in the case of displaced and trapped persons in conflict. Our combined use of remote sensing and kernel density calculation allows not only identifying the places likely to have sand fly habitat but also provides a measure of the likelihood of such habitats regionally. This $\mathrm{PDH}$ measurement can serve as a proxy for concluding risk or potential exposure to Leishmania when on-site analysis is not feasible. We find this crucial as there are narrow time windows (Chen et al., 2008; Zidi et al., 2013) for treating persons in conflict zones. This is especially the case within camps, where people have left their homes and are temporarily settled in another area, and it is of paramount importance due to the lack of immunity to regional strains of Leishmania following migration of displaced populations (Tripathi et al., 2007; Salam et al., 2014; Du et al., 2016). Although remote in origin, our results provide a picture of higher

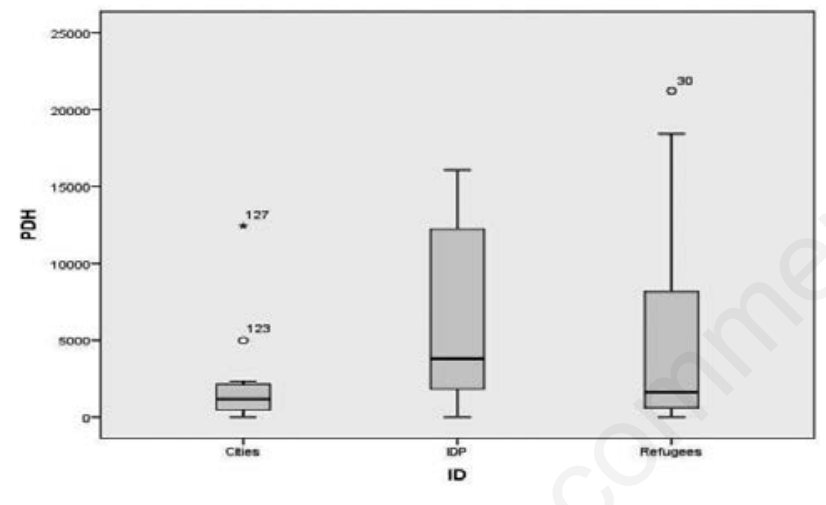

Figure 4. Boxplot of probable density of habitats (PDH) for Cities, internally displaced persons (IDP) camps, and Refugee locations.

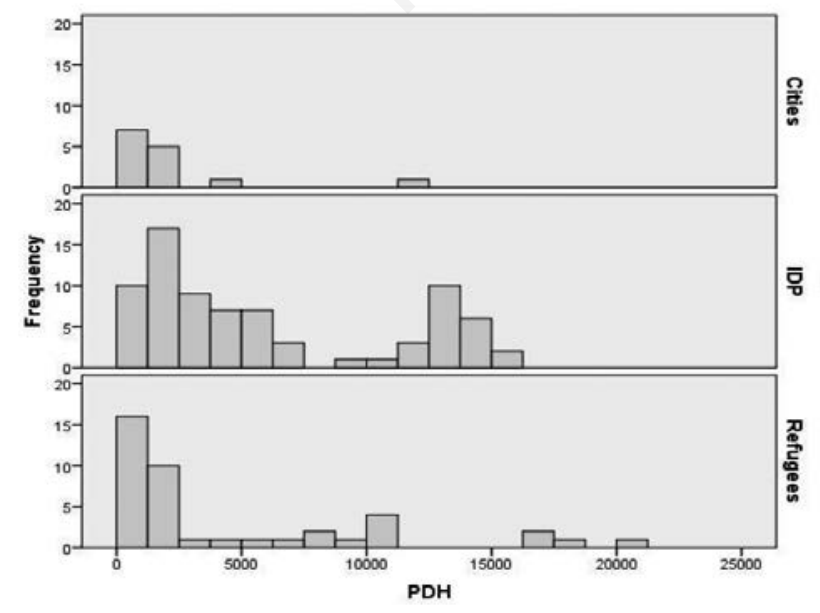

Figure 5. PDH for cities, IDP camps, and refugee locations. resolution of the risks inherent when dealing with vector-borne disease in displacements leading to collapsed health care systems ( $\mathrm{Du}$ et al., 2016).

IDP camps had the overall highest average PDH values while the major cities showed the lowest. Refugee sites in surrounding nations had the highest variance. The Refugee Sites, IDP camps, and cities had significantly different PDH values. Results show that people displaced within Syria have a higher risk of Leishmania exposure compared to the other populations in the study area.

We found it evident that the issue of leishmaniasis in camps should be a concern in Syria and all countries bordering Syria including the Turkish Hatay province, a prominent exiting point from Aleppo, Syria and a known hotspot for sand flies (Yaman and Özbel, 2004). A study comparing January 2009 and July 2015 found that the Syrian Civil War impacted the number of infections in the Southeast of Turkey (Özkeklikçi et al., 2017.) This is especially an issue in the urban areas of the region (Nimer, 2018).

Overall more concern needs to be given to IDP camps as these locations are more difficult to reach with emergency health care (Johnson, 2013) and house temporary residents frequently on the move (Taleb et al., 2015), but have the highest average PDH. Although it was suggested as an issue by Du et al. (2016), this was not evident in the analysis by Al-Salem et al. (2016) of leishmaniasis and conflict in Syria because only refugee camps were analyzed and there were no predictive spatial methods applied as it was reliant on recorded incidents. Prior studies of other IDP populations have found significant vector-borne illness cases in the war zones of Pakistan (Hussain et al., 2018) and the Democratic Republic of the Congo (Brooks et al., 2017). If possible, these and future locations should be monitored or continue to be monitored for the disease and the presence of sand flies.

Shortcomings of this analysis include verification and scale. As many of these places are difficult to reach, it will be more difficult to verify the presence of sand flies and leishmaniasis cases in different locations, especially those in ongoing war zones such as the IDP camps and cities. The movement of people between locations would also increase this difficulty. There is also the issue of MODIS' cell size of $250 \mathrm{~m}$ which leaves room for error due to undetected or falsely identified PDHs. The use of kernel density can partially circumvent this by measuring probability but may miss particularly isolated habitat sites. Another shortcoming is the magnitude of population migration and inability to survey in account for this (Du et al., 2016).

\section{Conclusions}

If locations cannot be directly monitored, we can at least know that they have a high likelihood of exposing persons to Leishmania infection because of their location. Relief efforts must be a high priority, based on the results of the analysis and specific to site.

Our process and results demonstrate the values of remote sensing and spatial analysis in the planning of relief in conflict zones. It provides a novel geospatial methodology for a continued analysis of PDHs and the potential for leishmaniasis cases in the area. It also provides a baseline for understanding public health in times of conflict, when verified on-the-ground data is in short supply or in difficult to reach locations with short time frames for relief and analysis. 


\section{References}

Alawieh A, Musharrafieh U, Jaber A, Berry A, Ghosn N, Bizri AR, 2014. Revisiting leishmaniasis in the time of war: the Syrian conflict and the Lebanese outbreak. Int J Inf Dis 29:115-9.

Al-Salem WS, Pigott DM, Subramaniam K, Haines LR, KellyHope L, Molyneux DH, Hay SI, Acosta-Serrano A, 2016. Cutaneous leishmaniasis and conflict in Syria. Emerg Infect Dis 22:931.

Berkley S, 2017. Syria, slums, and health security. Science 356:353.

Bithell JF, 1990. An application of density estimation to geographical epidemiology. Statist Med 9:691-701.

Brooks HM, Paul MKJ, Claude KM, Mocanu V, Hawkes MT, 2017. Use and disuse of malaria bed nets in an internally displaced persons camp in the Democratic Republic of the Congo: A mixed-methods study. PloS One 12:e185290.

Brownstein JS, Rosen H, Purdy D, Miller JR, Merlino M, Mostashari F, Fish D, 2002. Spatial analysis of West Nile virus: rapid risk assessment of an introduced vector-borne zoonosis. Vector-Borne Zoonot Dis 2:157-64.

Chen R, Sharman R, Rao HR, Upadhyaya SJ, 2008. Coordination in emergency response management. Commun ACM 51:6673.

Cross ER, Newcomb WW, Tucker CJ, 1996. Use of weather data and remote sensing to predict the geographic and seasonal distribution of Phlebotomus papatasi in southwest Asia. Am J Trop Med Hyg 54:530-6.

Diuk-Wasser MA, Brown HE, Andreadis TG, Fish D, 2006. Modeling the spatial distribution of mosquito vectors for West Nile virus in Connecticut, USA. Vector-Borne Zoonot Dis 6:283-95.

Du R, Hotez PJ, Al-Salem WS, Acosta-Serrano A, 2016. Old World cutaneous leishmaniasis and refugee crises in the Middle East and North Africa. PLoS Negl Trop Dis 10:p.e0004545.

Hansen M, Defries R, Townshend R, Sohlberg R, Dimiceli C, Carroll M, 2004. MODIS normalized difference vegetation index. Maryland, USA: The Global Land Cover Facility, College Park.

Hayani K, Dandashli A, Weisshaar E, 2015. Cutaneous leishmaniasis in Syria: clinical features, current status and the effects of war. Acta Dermato-Venereol 95:62-6.

Hussain M, Munir S, Khan TA, Khan A, Ayaz S, Jamal MA, Ahmed I, Aziz S, Watany N, Kasbari M, 2018. Epidemiology of cutaneous leishmaniasis outbreak, Waziristan, Pakistan. Emerg Infect Dis 24:159.

Inci R, Ozturk P, Mulayim MK, Ozyurt K, Alatas ET, Inci MF, 2015. Effect of the Syrian civil war on prevalence of cutaneous leishmaniasis in southeastern Anatolia, Turkey. Medical Sci Monitor: Int Med J Exper Clin Res 21:2100.

Rudaw, 2015. ISIS dumping bodies behind spread of 'flesh-eating' disease in Syria. Available from http://rudaw.net/NewsDetails.aspx?pageid=176153 Accessed: 11 November 2016.

Johnson G, 2018. No country for Syria's IDPs. Available from: http://www.aljazeera.com/indepth/features/2013/07/20137178 4449311867.html Accessed: 23 November 2016.
Koltas IS, Eroglu F, Alabaz D, Uzun S, 2014. The emergence of Leishmania major and Leishmania donovani in southern Turkey. Transact Royal Soc Trop Med Hyg 108:154-8.

Mitchel A, 2005. The ESRI Guide to GIS analysis, Volume 2: Spartial measurements and statistics. ESRI Guide to GIS analysis.

Mondragon-Shem K, Acosta-Serrano A, 2016. Cutaneous leishmaniasis: the truth about the 'flesh-eating disease' in Syria. Trends Parasitol 32:432-5.

Nimer NA, 2018. A review on emerging and reemerging of infectious diseases in Jordan: the aftermath of the Syrian crises. Canad J Infect Dis Med Microbiol 8679174.

Orshan L, Szekely D, Khalfa Z, Bitton S, 2010. Distribution and seasonality of Phlebotomus sand flies in cutaneous leishmaniasis foci, Judean Desert, Israel. J Med Entomol 47:319-28.

Özkeklikçi A, Karakuş M, Özbel Y, Töz S, 2017. The new situation of cutaneous leishmaniasis after Syrian civil war in Gaziantep city, Southeastern region of Turkey. Acta Trop 166:35-8.

Pigott DM, Bhatt S, Golding N, Duda KA, Battle KE, Brady OJ, Messina JP, Balard Y, Bastien P, Pratlong F, Brownstein JS, 2014. Global distribution maps of the leishmaniases. eLife 3:e 02851 .

Response SRR, 2017. Inter-agency information sharing portal. The UN Refugee Agency/UNHCR. Available from: http://data. unhcr. org/syrianrefugees/regional. php

Rouse Jr J, Haas RH, Schell JA, Deering DW, 1974. Monitoring vegetation systems in the Great Plains with ERTS. Available from: https://ntrs.nasa.gov/search.jsp?R=19740022614

Salam N, Al-Shaqha WM, Azzi A, 2014. Leishmaniasis in the Middle East: incidence and epidemiology. PLoS Negl Trop Dis 8:e3208.

Schilling V, 1921. Experiences of war hygiene in Turkey (Cilicia, North Syria). Beihefie Z Arch F Schiffs-u Trop-Hyg 25.

Sharara SL, Kanj SS, 2014. War and infectious diseases: challenges of the Syrian civil war. PLoS Pathog 10:e1004438.

Taleb ZB, Bahelah R, Fouad FM, Coutts A, Wilcox M, Maziak W, 2015. Syria: health in a country undergoing tragic transition. Int J Public Health 60:63-72.

Silverman BW, 2018. Density estimation for statistics and data analysis. London, New York: CRC.

Sokal RR, Rohlf FJ, 1969. The principles and practice of statistics in biological research. San Francisco, USA: WH Freeman and Company. pp 399-400.

Tripathi P, Singh V, Naik S, 2007. Immune response to leishmania: paradox rather than paradigm. FEMS Immunol \& Med Microbiol 51:229-42.

United Nations High Commissoner fpr Refugees (UNHCR). UNHCR Syria Regional Refugee Response. Available from:

http://data.unhcr.org/syrianrefugees/regional.php Accessed: 07 November 2016.

World Health Organization (WHO), 2015. Leishmaniasis Fact sheet N. 375.

Yaman M, Özbel Y, 2004. The sandflies (Diptera: Psychodidae) in the Turkish province of Hatay: some possible vectors of the parasites causing human cutaneous leishmaniasis. Ann Trop Med Parasitol 98:741-50.

Zidi K, Mguis F, Borne P, Ghedira K, 2013. Distributed genetic algorithm for disaster relief planning. Int J Comp Commun Control 8:769-83. 